\title{
The Constraints Governing Multiple Wh_Questions in Kuwaiti Arabic: A Syntactic Study
}

\author{
Ahlam Saleh Al_Enezi* \\ University of Jourdan, Jordan \\ Corresponding Author: Ahlam Saleh Al_Enezi, E-mail: Ahlam.s.alenezi@gmail.com
}

\section{ARTICLE INFO}

Article history

Received: March 07, 2018

Accepted: May 12, 2018

Published: August 31, 2018

Volume: 9 Issue: 4

Advance access: July 2018

Conflicts of interest: None

Funding: None

Key words:

Syntax,

Constraint,

Analysis,

Wh-word,

Multiple Wh-questions,

Kuwaiti Arabic.

\begin{abstract}
The purpose of this study is to discuss the vagueness in multiple wh questions in the spoken Kuwaiti Arabic (KA) in order to sharpen it up in some way. This study tries to provide a basic analysis for the construction of this process in KA. Some differences in the syntax and structure of other languages are mentioned to highlight the differences between them. Furthermore, this study provides some piece of evidence to support the claim of how the multiple wh_ questions are structured in KA and what constrains govern them. The study concluded with some recommendations including more researches in the different aspects of the KA syntax.
\end{abstract}

\section{INTRODUCTION}

Language is a cognitive ability of humans and it is extremely complex. It will not be easy to describe and dig deep down in the structure of any language. Therefore, it is helpful to divide a language into different components according to different shared characteristics. These components and categories are classified according to syntactic means, where syntax is the study of describing how words form grammatical meaningful sentences and utterances. It is essential to emphasize that grammatical forms are not essentially meaningful forms. In syntax, analyzing and describing how sentences are structured is governed by how these sentences are well-formed. Therefore, the science of syntax belongs to the cognitive science. For instance, any human being has a number of neurons in his brain operating together to articulate some meaningless letters/sounds appropriately. In addition to these neurons, there are another group of neurons make these letters or sounds coherent ideas. Translating these sounds/letters into coherent ideas is the responsibility of syntax (Carnie, 2002). Questions are one of the important components of syntax. The question is a phrase seeking information and ending by a question mark, which is indicated by the symbol (?).
There are different types of questions in KA and other languages, such as the yes/no questions and wh-questions. Wh- questions contain wh-word/s and the wh-word contains an interrogative word that begins by wh in English and similar words in other languages. In Kuwaiti Arabic (KA), whwords can be shown in many expressions, such as [we: $\mathrm{n}$ ] 'where', [minu] 'who', and [?aj] 'which'. Similar to English and many languages, wh-questions in KA are either echoic or non-echoic. Echoic question is a question ending with a whword asking about something that is already said by another person, such as in [?ihja rajha we: $n$ ?] 'she is going where?' where the speaker responses to another speaker talking about a female going to somewhere. Non-echoic questions is the usual form of questions beginning by a wh-word and ask another person about information as in [we: $n$ Prhja rajha?] 'where is she going?'. The difference between these two questions is not only in their structures and where the whword locates but also in that echoic questions are normally responds to another speaker about something previously mentioned and non-echoic ones are questions that seek new information. Obviously, echoic and non-echoic questions differ in the positions occupied by the wh-words. Moreover, questions not always contain single wh-word, some KA questions contain more than single wh-word in one question. 
These questions are known by multiple wh-questions, in which a question contains more than single wh-word in the same question. Therefore, this study investigates the process of structuring the multiple wh-questions in KA. Evidence from some other languages will be used, but our main focus will be on the syntax of multiple wh-question of KA. Examples from KA is used to explain the structure of this process in $\mathrm{KA}$ and how it differs from other relative languages.

\section{Questions of the Study}

This study is a syntactic study that is restricted to investigate the multiple wh-questions in Kuwaiti Arabic to answer the following questions:

1. Does multiple wh-questions occur in Kuwaiti Arabic? If yes, how do they are constructed?

2. What is the constraints and rules governing this process in Kuwaiti Arabic?

\section{Significance of the Study}

Although many studies have been done on the construction of multiple wh-questions in many languages, including some Arabic dialects, little has been done on Kuwaiti Arabic. The current study covers this syntactic aspect by explaining how it is constructed in detail and what constraints and rules governing the application of this process in $\mathrm{Ku}-$ waiti Arabic.

\section{Limitation of the Study}

This study also has some limitations. For example, it is limited to studying the construction and constraints of structuring the multiple wh-questions in Kuwaiti Arabic. Another limitation is that it ignores any other type of questions in Kuwaiti Arabic.

\section{LITERATURE REVIEW}

To describe any phenomenon in syntax it is essential to look at sentences which speakers of that language already considered to be syntactically well-formed sentences (Thomas, 1993). One of the important features of human language is displacement. In syntax, displacement is found when some elements of a sentence/phrase appear in positions different than those where they interpreted. Typically, this is the case of some wh words in Arabic questions (Aoun, Benmamoun \& Choueiri, 2010).

According to Carnie (2002), in the wh_ questions the wh word appears in a position far away from the place where its theta-role is assigned. In other words, A multiple wh-question is a type of question that contains more than one wh-word, whose answer is a set of sentences in which an appropriate non-wh-word replaces the wh-word.

In English, the Superiority Effect requires that when a clause contains two wh-words, the one that undergoes wh-movement is the one closest to the interrogative C. In fact, Superiority Affect chooses the subject over the object, and the higher object over the lower object. The existence of superiority effect suggests that $\mathrm{C}$ gets to pick what wh moves to it, which leads us to one of the Universal Grammar principles, namely Attract Closest Condition and Wh-Attraction Condition (Aoun \&Li, 1993a).

McClodky (1990) assumed that some languages allow not only multiple wh-words, but also allow both a wh-phrase and an overt complementiser, such as Iresh. However, Standard Arabic (SA), usually doesn't allow wh_words to remain in situ. Similarly, English and KA in most cases don't allow wh_words to remain in situ. On the other hand, in other varieties as Egyptian Arabic/EA that is not the case, because EA usually allows all its wh_words to remain in situ in all contexts (Carnie,2002).

Wahba (1984) investigated wh-questions in Egyptian Arabic. She classified the wh-expressions into two main sets, namely nominal and non-nominal wh-expressions. However, Wahba did not explain how she classified them nor what criteria did she use in her classification. She also argued that Egyptian Arabic does not show clear constrains specifying the wh-words that can appear in situ. In Egyptian Arabic, adverbial wh-words in both simple and complex wh-questions are allowed. In other words, Egyptian Arabic allows all the wh-words to remain in situ.

Shlonsky (2002) discussed the wh-questions in Palestinian Arabic. Shlonsky argued that Palestinian Arabic use Class II interrogatives, as he called, to form its wh-questions. His analysis covered all the differences between the constructions and wh-questions that have resumptions. In other words, he described the relativizer in Class II interrogatives, the acceptability of the Arabic correspondence of 'what' in these constructions, and the agreement facts with [mi: n], [man], and [Jkun] 'who'. Moreover, he argued about null pronominal as subject and Class II interrogatives in this dialect. Moreover, he argued about some contrasts in Moroccan Arabic wh-questions.

According to Aoun, Benmamoun \& Choueiri (2010), all nominal wh-expressions in Lebanese Arabic, except the Lebanese wh-expression [fu: ] 'what', are allowed to remain in situ. They argued about the distinction between referential and non-referential adverbial wh-expressions in Lebanese Arabic when they undergo long-distance extraction. According to them, Lebanese Arabic allows the referential adverbial wh-expressions to remain in situ in both simple and complex sentences; however, the non-referential adverbial wh-expressions are only allowed to occur in Lebanese Arabic simple sentences.

Typically, there are four language types with respect to possibilities for wh-movement in multiple questions: English-type, where only one wh-phrase moves because the WH features in English are strong; Chinese-type, where they all stay in situ because the WH in Chinese are week; Frenchtype, where both of these options are available; and Bulgarian-type, which front both of the wh-words and allow moving them. In addition to some languages like the Standard Arabic do not allow any of their wh-expressions to remain in situ (Ouhalla,1996).

Moreover, Ouhalla argued that Iraqi Arabic allows whwords to remain in situ. He argued that the ability of a noun 
phrase (NP) has to be a bound variable with no relation to its inherent features, namely all the types of NP in Iraqi Arabic are allowed to operate as bound variable. In adiition, he argued about the relationship between the presence of an overt pronominal trace on wh-words as [Jinu] 'what' and [minu] 'who' in Iraqi Arabic and he categorized them as compound Iraqi wh-words (ibid).

In fact, this study concerns with the KA in particular, therefore a data from KA is provided in order to analyse it and trigger the conditions and constraints it follows in its multiple wh-movements, overtly and covertly.

\section{METHOD OF THE STUDY}

There are many wh-words in KA, such as [Paj] 'which', [we: n] 'where', [le:f] 'why', [Jinu] 'what', [flo: n] 'how', [tam] 'how many/much', and [minu] 'who'. Any KA wh-question has one or more from these wh-words. For example, multiple wh-questions in KA contains more than one wh-word. Three examples were taken randomly from every day conversations among Kuwaitis. These typical multiple wh-questions in KA were chosen to analyze them and study their structure, each question will be followed by a description of its structure, descriptive diagram, and an analysis of the movements in each one supported by different syntactic rules and constraints. Similar questions in related languages are also used to support our analyses and descriptions.

\section{DATA \& DISCUSSION}

As mentioned earlier three typical multiple wh-questions in KA are chosen. KA wh-words are indicated from other words in the question by being bold. Structuring these three forms are similar to structuring hundreds of multiple wh-questions in KA; therefore, discussing how they are built helps linguists and people interested in KA syntax to understand why these questions differ than many multiple wh-questions having similar meanings in other Arabic dialects. The chosen three multiple wh-questions in KA are as follows:

1-Saba: la minu kisar $\int \mathrm{inu}$

past.intr-think-s-m who past.intr-break what

'He thinks who broke what?'

2-le: s sa?al minu ma: $t$

why past.intr-ask-3-s who past-die

'Why did he ask who died?'

3-minu IXtartaj ?aj dikt: or

whom past.intr-choose-2-s-f which doctor-s-m

'Whom did you choose, which doctor?'

The first two examples ' $1-2$ ' are non-echoic questions in which either or both of the wh-words are preposed, whereas the fourth one is an echo question in which the wh-word 'who' [minu] is preposed and the wh-word 'what' [ $\mathrm{Inu}]$ remained in situ. In (2) each one of the whwords is moved to $\mathrm{CP}$, one in the main clause and one in the relative clause. In (3) only one of the two wh-words is preposed and the other one remains in situ, similar to the echo question in (1).

To better understand why certain items can be preposed and others can't, let's take a closer look at the derivation of a sentence of each, in order to capture the constraints that regulate and organise these movements.

In (1) the verb break [kisar] with the interrogative pronoun what ( $\mathrm{Inu}$ ) to form the VP [kIsar $\left.\int \mathrm{Inu}\right]$. The past tense affix merges with this VP to form the T-bar [past-kIsar $\int \mathrm{Inu}$ ], and this in turn merges with the interrogative pronoun who [minu] to form the TP [mInu kisar $\left.\int \mathrm{Inu}\right]$. The resulting TP is merged with a null declarative complementiser with an edge feature, to form the C-bar. The edge of feature on $\mathrm{C}$ enables it to attract a wh-expression which it c-commands to move to become the specifier of $\mathrm{C}$. But there is an obvious problem which rises here, since there are two different wh-words c-commanded by the null complementiser, namely minu and $\int \mathrm{inu}$. Since $\mathrm{C}$ can only attract a single wh-expression to move to spec-C, it is clear that only one of these two whwords can move to spec_C.

Since minu is higher up in the structure than finu, such sentences provide evidence for the existence of a superiority effect which states that the requirement for $\mathrm{C}$ to attract the higher wh-expression in the structure and $\mathrm{C}$ has to attract the closest interrogative word which it c-commands according to the Attract Closest Condition/ACC, and also according to the Relativised Minimality Condition/RMC with the Economy Condition/EC that gives economy considerations require us to move the smallest constituent possible the shortest distance possible. And since the Chain Uniformity Condition/CUC tells us that only a maximal projection can be attracted to move into s specifier position, the various conditions which the UG imposes on movement man that wh-mivement will in effect be subject to the Wh-Attraction Condition which requires us first to identify the closest wh-word to $\mathrm{C}$, and then move the smallest possible maximal projection containing it to spec-C; if that's barred for some readon, we move the next smallest maximal projection containing the wh-word. In accordance with the ACC, C identifies minu as the closest wh-word, and in compliance with the CUC and the EC attracts the smallest possible maximal projection containing minu to move to spec-C. However, since minu is itself a maximal projection, this means that minu is attracted to move to spec_C. Wh-movement leads to deletion of the edge of feature on $\mathrm{C}$, and to the original occurrence of minu ultimately being given a null spellout.

The derivation continues by merging the $\mathrm{CP}$ as the complementiser of the verb think (Cabala), forming the VP minu O minu kisar $\int \mathrm{inu}$. This VP is then merged with the Tense affix of present to form the T-bar, and this in turn merges with a null pronoun to form the TP. The resulting TP is then merged with a $\mathrm{C}$ constituent of a null complementiser to form the $\mathrm{CP}$ in the main clause. In fact, this kind of derivation is very similar to the echo questions in English and the evidence is based on the assumption that the edge of feature on $\mathrm{C}$ is immediately deleted once $\mathrm{C}$ has attracted the closst wh-word, 
it follows that no more than one wh-word can be moved to the front of any given clause (Radford, 2009), so forming the following structure:
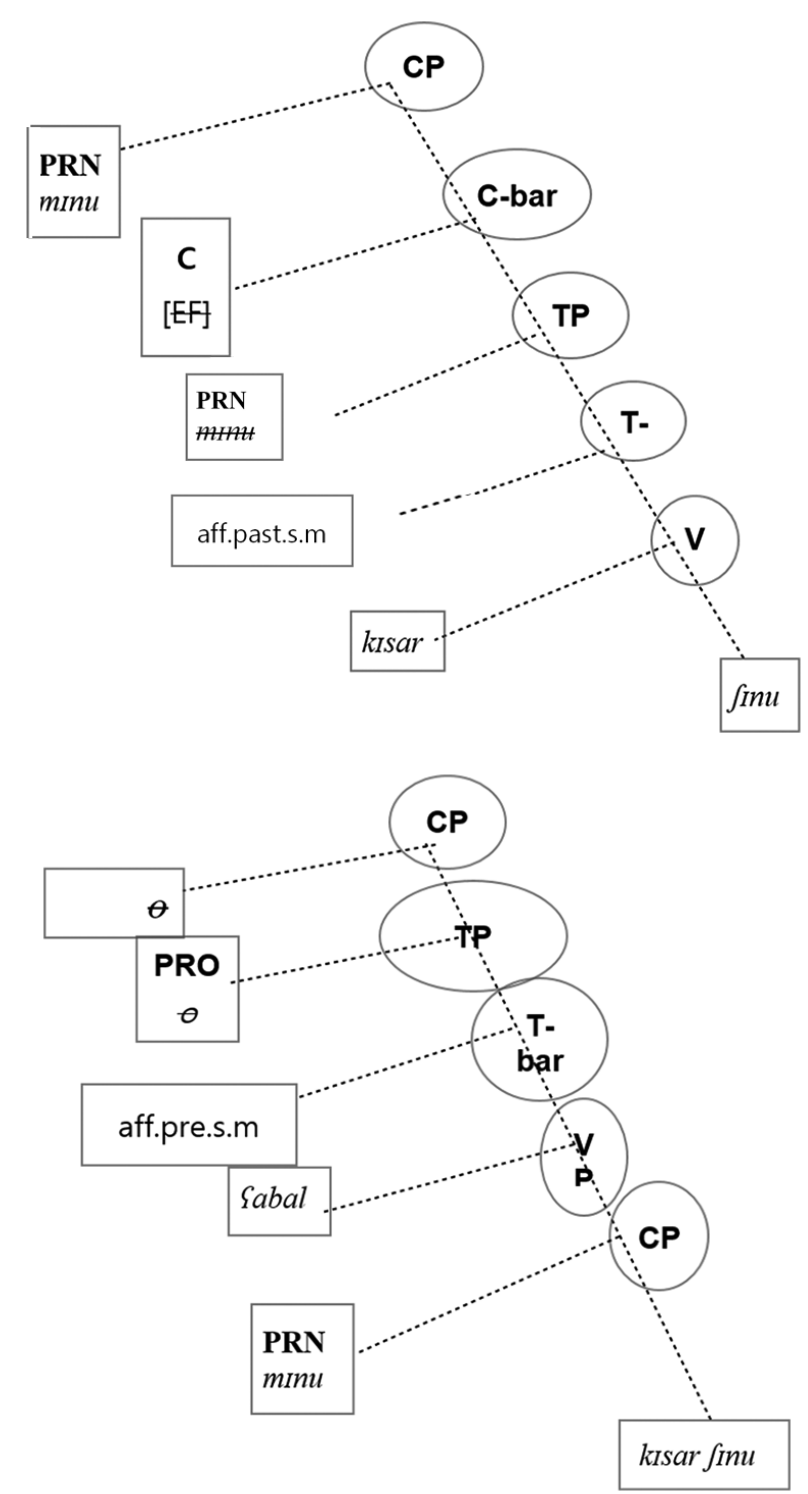

Similarly, in (2) we have a case of two interrogative words, one in the main clause and the second one in the relative or imbedded clause, [lee $\int$ sa?al minu ma: $t$ ]. To drive the structure of 3 we start with merging the verb die [maat] with the interrogative pronoun what [mInu] to form the VP [ma: $t$ minu]. The past tense affix merges with this VP to form the T-bar [past-ma: $t$ minu], and this in turn merges with the null pronoun, to form the TP (O maat minu). The resulting TP is merged with a null declarative complementiser with an edge feature, to form the C-bar. The edge of feature on $\mathrm{C}$ enables it to attract a wh-expression which it c-commands to move to become the specifier of $\mathrm{C}$, the wh-word 'minu' is moved to spec_C via Wh-Movement leaving its silent copy as complement on VP. In fact, Wh-movement leads to deletion of the edge of feature on $\mathrm{C}$, and to the original occurrence of minu ultimately being given a null spellout.
Then merging the $\mathrm{CP}$ as the complement of the verb ask [saPal], to form VP. This VP is then merged with the tense affix that indicates the past tense and third person to form the T-bar, and this T-bar in turn merges with the interrogative pronoun [lee $\left.\int\right]$ to form TP. The resulting TP is then merged with a null declarative Complementiser with an edge feature to form the C-bar. The edge feature on $\mathrm{C}$ enables it to attract a wh-word which it c-commands to move to become the specifier of $\mathrm{C}$. Therefore, the edge feature on $\mathrm{C}$ attracts the closest interrogative pronoun, namely [lee $\left.\int\right]$ to move to become the specifier of $\mathrm{C}$, so forming the following structure:

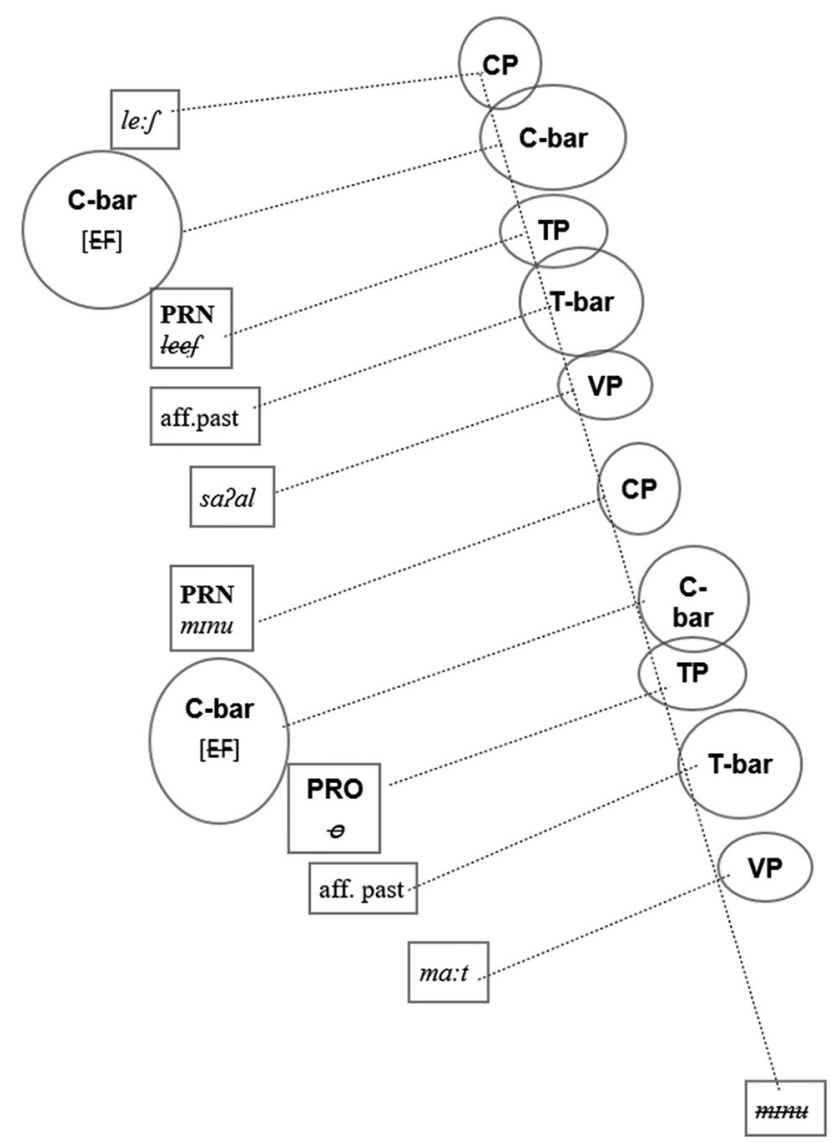

In (3) we have another case that a sentence contains two wh-words, namely a wh-word with a wh-phrase 'QP'. In deriving the structure of [minu IXtartaj Paj dikto: $r$ ], we start from merging the quantifier [?aj] with the noun [dikto: $r$ ] to form the QP. This in turn merged with the verb choose [IXtartaj] with the interrogative pronoun what [mInu] to form the VP [mInu IXtartaj]. This in turn merged with the verb choose [IXtartaj] to form the VP [IXtartaj ?ay dikto: $r$ ]. The resulting VP is subsequently merged with the past tense female singular affix to form the T-bar, which in itself merged with the interrogative pronoun whom [minu] to form the TP. The resulting TP is merged with a null declarative complementiser with an edge of feature, to form the C-bar. Here also the edge feature on $\mathrm{C}$ enables it to attract a wh-word which it c-commands to move to become the specifier of $\mathrm{C}$. Therefore, the edge feature on $\mathrm{C}$ attracts the closest interrogative pronoun, namely $[\mathrm{mInu}]$ to 
move to become the specifier of $\mathrm{C}$, so forming the following structure:

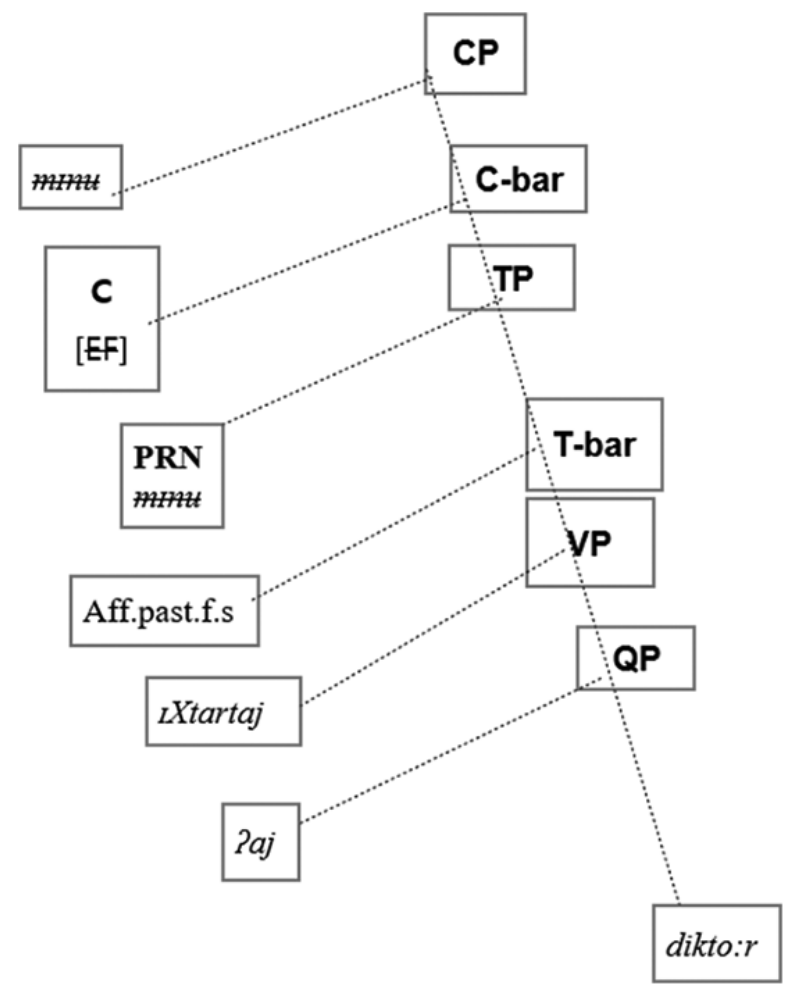

Besides the UG principles, a number of evidences are used to support the previous analysis. The first evidence is, given the assumption that in $\mathrm{KA}$, which is similar to English, the edge of feature on $\mathrm{C}$ is immediately deleted once $\mathrm{C}$ has attracted the closest wh-expression. It follows that no more than one wh-expeession can be moved to the front of any given clause (Radford, 2009).

The second evidence is given from the phenomenon $\mathrm{pf}$ wh-copying in child language to prove the process of moving the wh-words overtly. For instance, a child may say '*laSab-tu wiən' instead of [wıən laSab-tu] and say '*laSab mInu' '*laSab $\int$ Inu 'instead of [mInu laSab $\left.\int \mathrm{Inu}\right]$ which is also related to the third evidence below. Moreover, according to Ouhalla's (1996) classification of language types according to their possibilities for wh-movement in multiple wh-questions, KA seems to be similar to the French type. In other words, multiple wh-questions in KA allow moving only one wh-phrase as well as allowing all the wh-words to remain in situ.

\section{CONCLUSION}

This paper has discussed a syntactic issue of structuring the multiple wh-questions in KA. It showed that all the motivations for movement then seem to be locality constraints. That is, two items must be near or local to one another. Furthermore, moving any wh-expression in any language is not arbitrary, there is always a reason that motivates and forces this transformation to apply. It is also constrained in that moving something may apply only if you have to and this movement doesn't violate any of the UG constraints. In fact, this field needs many experiments to add and to be considered as an empirical evidence for many ideas and hypotheses. Therefore, I would recommend more work in the field of multiple Wh-questions of KA by using or trying different models and analysis.

\section{REFERENCES}

Aoun, J., Benmamoun, E., and Choueiri, L. (2010). The Syntax of Arabic. New York, Cambridge University Press.

Aoun, J., and Li, A. (1993a). Syntax of Scope. Cambridge, Mass.: MIT Press.

Carnie, A. (2002). Syntax: A Generative Introduction. Blackwell Publishing Ltd, UK.

Grebenyova, L. (2012). Syntax, Semantics and Acquisition of Multiple Interrogatives: Who wants what?. John Benjamin, Philadelphia: USA.

McCloskey, J. (1990). Presumptive Pronouns, A-binding and Levels of Representations in Irish. In Syntax and Symantics 23: Syntax of the modern Celtic Languages, ed. Randall Hendrich, 99-248. San Diego: Academic Press.

Ouhalla, J. (1996). Remarks on the Binding Properties of wh-pronouns. Linguistic Inquiry 27: 680707.

Radford, A. (2009). English syntactic Structure. New York, Cambridge University Press.

Thomas, L. (1993). Beginning Syntax. Blackwell Publishing Ltd, UK. 